\title{
Impact of Educational Materials on the Duration of Exclusive Breastfeeding Assured by Women Who Delivered at the Souissi Maternity Hospital in Rabat
}

\author{
Amina Bennis ${ }^{1 *}$, Fatima Zahra Laamiri ${ }^{1,2}$, Anas Ansari Chebguiti ${ }^{3}$, Hassan Aguenaou ${ }^{4,5}$, \\ Mustapha Mrabet ${ }^{1}$, Aicha Kharbach ${ }^{1}$, Amina Barkat ${ }^{1}$
}

\author{
${ }^{1}$ Research Team in Maternal and Child Health and Nutrition, Faculty of Medicine and Pharmacy, Mohammed V University, \\ Rabat, Morocco \\ ${ }^{2}$ Higher Institute of Nursing Professions and Technical Health, Rabat, Morocco \\ ${ }^{3}$ Department of Obstetrics, Gynaecology and High Risk Pregnancies, Maternity Hospital Souissi-Ibn Sina Teaching Hospital of \\ Rabat-Salé, Rabat, Morocco \\ ${ }^{4}$ Moroccan Association of Infant Nutrition, Rabat, Morocco \\ ${ }^{5}$ Mixed Research Unit in Nutrition and Food URAC 39, (University Ibn Tufail-CNESTEN) Designated Regional Center of \\ Nutrition Associate AFRA/IAEA, Kenitra, Morocco
}

Email: *aminabennis.bc@gmail.com, barakatamina@hotmail.fr

How to cite this paper: Bennis, A., Laamiri, F.Z., Chebguiti, A.A., Aguenaou, H., Mrabet, M., Kharbach, A. and Barkat, A. (2017) Impact of Educational Materials on the Duration of Exclusive Breastfeeding Assured by Women Who Delivered at the Souissi Maternity Hospital in Rabat. Open Journal of Obstetrics and Gynecology, 7, 1300-1318.

https://doi.org/10.4236/ojog.2017.713133

Received: November 1, 2017

Accepted: December 19, 2017

Published: December 22, 2017

Copyright $\odot 2017$ by authors and Scientific Research Publishing Inc. This work is licensed under the Creative Commons Attribution International License (CC BY 4.0).

http://creativecommons.org/licenses/by/4.0/

c) (i) Open Access

\begin{abstract}
Background: The practice of exclusive breastfeeding (EB) in Morocco has witnessed a worrying decline in recent decades, contrary to the recommendations of the World Health Organization (WHO) which advocates it during the first six months as a significant public health tool. The present study aims to assess the impact of educational materials on mothers' behaviour with regard to keeping up EB as long as six months, at least. Methods: This is a cohort study with a prospective collection of data over a period of one year, through a questionnaire-based survey of 500 women who delivered at the Souissi Maternity Hospital in Rabat. The subjects were divided into an intervention group sensitized, during the medical visit, by means of information delivered orally about breastfeeding and a booklet containing instructions on breastfeeding management and the benefits of EB, especially when extended for the first six months; and a control group attending the same operation with no awarenessrising through educational materials. To assess EB rates, the subjects had been followed for six months through telephone. Results: 372 women who delivered were followed, 194 from the intervention group and 178 from the control group. The remaining 128 women not followed were lost sight of. A higher percentage of mothers in the intervention group exclusively breastfed their
\end{abstract}


babies up to the age of six months compared to the control group, $55.2 \%$ against $38.8 \%(\mathrm{p}=0.002)$. The main reason produced by most mothers who ceased to exclusively breastfeed their babies is milk insufficiency. Conclusion: The postnatal nutritional education strategy based on the distribution of educational materials has considerably raised the number of women who exclusively breastfed their babies until the age of six months.

\section{Keywords}

Exclusive Breastfeeding, Educational Material, Duration, Postnatal Period, Breastfeeding Practices

\section{Introduction}

Breastfeeding offers significant short-term and long-term environmental, psychosocial, economic, and particularly health benefits for the infant, mother and community [1] [2]. It is one of the few interventions in which survival benefits extend throughout childhood [3]. Indeed, breast milk is the safest, fullest and most ideal food a mother can offer to her newborn, given that it contains all the nutrients the baby needs in the first six months of life [4].

Breastfeeding reduces child mortality and morbidity, and enables children to enjoy good health and optimal growth and development [5]. Breastfeeding has been shown to be associated with lower rates of respiratory and gastrointestinal diseases, otitis media and allergies. Breastfed infants also face a low risk of sudden infant death syndrome, insulin dependent diabetes and cancer during childhood. It equally prevents obesity during childhood and adolescence as well as cardiovascular risks [5] [6] [7]. In addition, breastfeeding has a cognitive benefit, particularly in terms of mental health, early brain development, optimal neuronal development, cognitive ability, school performance and linguistic ability [8]. For mothers, benefits include decreased postpartum blood loss, uterine involution, and weight stabilization [6]. Also, breastfeeding helps improve maternal health by reducing the risk of cardiovascular diseases, postpartum depression, ovarian cancer and breast cancer [9].

As a matter of fact, health benefits are much more guaranteed and improved when $\mathrm{EB}$ endures into the first six months than with partial breastfeeding [2] [10]. For optimal development and health, as set out in the Global Strategy, WHO and UNICEF (United Nations International Children's Emergency Fund) recommend that infants should be exclusively breastfed during the first six months of life (180 days) [11], thus preventing more than 800,000 child deaths worldwide each year [5]. Several studies have shown a cause-and-effect relation indicating that exclusive breastfeeding for six months, with no consumption of fluids or food, and subsequently continuation thereof as an important component of the infant's diet, is linked to great benefits for children [12].

Unfortunately, world breastfeeding rates (especially exclusive breastfeeding) 
remain sub-optimal [10]. In Morocco, the rates of exclusive breastfeeding dropped from $51 \%$ in 1992 to $32 \%$ in 2004 . In 2006, the rate dropped further to $15 \%$ to go up to $27.8 \%$ in 2011 , representing a decrease of $23.2 \%$ in 19 years. It has been found that the living environment affects this type of behaviour: thus, children living in rural areas benefit from more exclusive breastfeeding (30.5\%) than children living in urban areas (24.4\%) [13] [14].

Several factors related to the child, work and socio-demographic situation affect mothers' decision with regard to breastfeeding. Findings from studies in developed and developing countries have shown that pregnant women harnessed with better knowledge about breastfeeding are more likely to offer breastfeeding, and to follow breastfeeding recommendations afterwards [10]. As a result, educational or support programs play a crucial role in shaping mothers' knowledge and views, enabling them to make informed decisions about infant nutrition [15]. Studies designed to test the effectiveness of intervention in the extension of breastfeeding to six months have concluded that prenatal education on breastfeeding is not enough to extend the duration, and that intervention during both prenatal and postnatal periods might be more effective [16]. In 2012, the Cochrane study (52 studies, 56,451 mother-infant pairs, 21 countries) found that postnatal support increases both the duration of breastfeeding and exclusive breastfeeding [17].

To improve health in the short term, WHO and UNICEF are working to promote breastfeeding as a key strategy and indispensable component of life programming, such a position is supported by most health ministries and professional organizations [18]. For its part, the Moroccan health ministry has established the 2011-2019 national nutrition strategy, which aims, inter alia, to ensure the promotion and support of breastfeeding as well as the creation of favourable environment for breastfeeding good practices [14].

This study aims to assess the impact of educational materials, distributed on the day after delivery, on mothers' behaviour in order to maintain exclusive breastfeeding for at least six months. This would allow the achievement of the objectives set out in the 2011-2019 national nutrition strategy.

\section{Materials and Methods}

\subsection{Type and Location of Study}

This is a prospective study conducted over a period of 13 months (October 2015 - November 2016) at the Ibn Sina University Hospital, more particularly at the Souissi Maternity Hospital in Rabat, a reference hospital in Morocco, receiving almost 18.000 births annually (40 births per day).

\subsection{Sample Size and Sampling Procedure}

The sampling method used in this study is probabilistic. The survey was carried out on all women who were cared for by the Souissi Maternity Hospital in Rabat. From this population and based on a national prevalence of $27.8 \%$ [13] and an 
accuracy of 5\%, a minimum population of 308 is required. In this work, the survey has been conducted among 500 women who were divided into two groups. Recruitment lasted approximately 7 months (October 2015 - April 2016) and took place on the first day after the participants gave birth. A list of mothers who had just had a normal baby born was established based on the postnatal day care registry at the hospital. Based on the list, all mothers were pre-selected to be eligible and then informed of the study and personally invited to participate.

\subsection{Study Population}

\subsubsection{Inclusion Criteria}

In this study, we included all women who delivered vaginally, mothers of singletons, born between 37 and 41 weeks of amenorrhea, and having a mobile phone.

\subsubsection{Exclusion Criteria}

Women who delivered by caesarean section, who had low birth weight newborns $(<2500 \mathrm{~g})$, premature, or hospitalized newborns were excluded from the study.

Cesarean delivery women were excluded because most of them are not well awake (effect of anesthesia) and can't breastfeed in the first hours after delivery, while our study is based on postpartum recruitment of women, in addition to the objective of following the practice of breastfeeding just after birth.

\subsubsection{Distribution of Recruited Women}

During the study period, the women recruited were divided into two groups: an intervention group and a control group. The intervention group women ( $\mathrm{n}=$ 250) were first sensitized through a short educational session (10 minutes) that included information delivered orally during the medical visit on the benefits of breastfeeding for women and their infants, mainly EB by shedding light on its definition, and the good practices of breastfeeding as well as the production of breast milk. During the session, mothers were encouraged, whenever necessary, to ask questions about breastfeeding and to express their views. Afterwards, the women received an educational booklet on the intervention, in Arabic and French, containing illustrations and information on: the benefits of breast milk, the importance of skin-to-skin contact immediately after birth, the importance of early breastfeeding and giving colostrum to the baby, the criteria of good positioning for corrective breast-taking, the signs of effective suckling, the signs of effective breastfeeding for the first six months, on-demand breastfeeding and its daily frequency, breastfeeding accessories, techniques for collecting and storing breast milk, and questions and answers about different maternal concerns (depression, hygiene, nipple pain, quantity of milk produced, duration and number of feedings, mixed feeding, diet to be followed during breastfeeding, mothers' illness and breastfeeding, weaning of the baby, etc.)

Women in the control group $(n=250)$, however, benefited only from the usual oral awareness-raising operation (short educational session) without edu- 
cational materials.

Our intervention was based on the WHO guidelines and the terms were defined according to their data.

\section{Definition of exclusive breastfeeding}

Breastfeeding is exclusive when babies are fed only breast milk or expressed milk, and receive no other liquid or solid, not even water, with the exception of oral rehydration solutions, medicines, minerals or vitamins drops or syrups [11].

\subsection{Data Collection}

In order to study all aspects related to the topic, we used a reference questionnaire prepared by nutrition and breastfeeding experts, which had been tested, modified and validated two months before our research team ${ }^{1}$ started the study (following a pilot study conducted on 20 women to determine whether the questions were clear and understandable), and then administered in a standardized fashion to women in both groups (intervention group and control group). Data collection was carried out in two stages. Firstly, we filled out the questionnaire designed for mothers who had delivered at the maternity, subject of the study, following a face-to-face interview with participants from both groups at the delivery place. Our interview included the socio-demographic, prenatal and natal information about mothers and newborns, as well as information related to mothers' knowledge and practices of breastfeeding.

Secondly, we completed the questionnaire with a follow-up sheet of breastfeeding mothers through telephone interviews with each participant on the $2^{\text {nd }}$ day, first week, $3^{\text {rd }}$ and $6^{\text {th }}$ months after delivery.

\subsubsection{Mothers' Socio-Demographic Information}

The socio-demographic variables collected from the mothers who delivered were:

- Age: quantitative variable;

- Living area: divided into urban, peri-urban and rural areas;

- Education level: divided into 5 categories: illiterate, literacy courses, primary school, secondary school, university;

- Mother's profession: the participants were categorized into three groups: housewives, employees or other.

\subsubsection{Prenatal and Natal Information of Mothers and Newborns}

For mothers, we included information about the number of children, pregnancy follow-up, the number of pre-natal visits, the place of follow-up, as well as the delivery method. Infants' data only concerned the Apgar score and birth weight.

\subsubsection{Information Related to Mothers' Breastfeeding Knowledge and Practices}

The major data collected were:

- Maternal knowledge about breastfeeding: early breastfeeding, milk produc-

${ }^{1}$ Research Team in Maternal and Child Health and Nutrition, Faculty of Medicine and Pharmacy/ Mohammed V University, Souissi, Rabat, Morocco. 
tion, intended breastfeeding duration, breastfeeding benefits;

- Mothers' breastfeeding practices: first feeding time, administration of other liquids, position of the newborn, breast-taking, sucking;

- Breastfeeding difficulties: problem type and timing;

- Nipples condition;

- Milk production index.

\subsubsection{Information Related to the Follow-Up of Breastfeeding Mothers with Regard to EB}

In the follow-up sheet, we have retained the following parameters:

- Exclusive breastfeeding duration stratified into EB on the $2^{\text {nd }}$ day, EB in the $1^{\text {st }}$ week, EB in the $3^{\text {rd }}$ month, and EB in the $6^{\text {th }}$ month;

- Babies' nutritional alternatives, in case EB discontinuation, subdivided into several methods: Breast and pharmacy milk, Breast and cow milk, Breast and complementary food, Pharmacy milk alone, Cow milk alone, Pharmacy milk and complementary food, Breast, pharmacy milk and complementary food, Cow milk and complementary food or other;

- Cause of EB discontinuation: infant illness, return to work, milk insufficiency, mother illness, new pregnancy, breastfeeding difficulty or other.

Figure 1 summarizes the flow of participating women during the study.

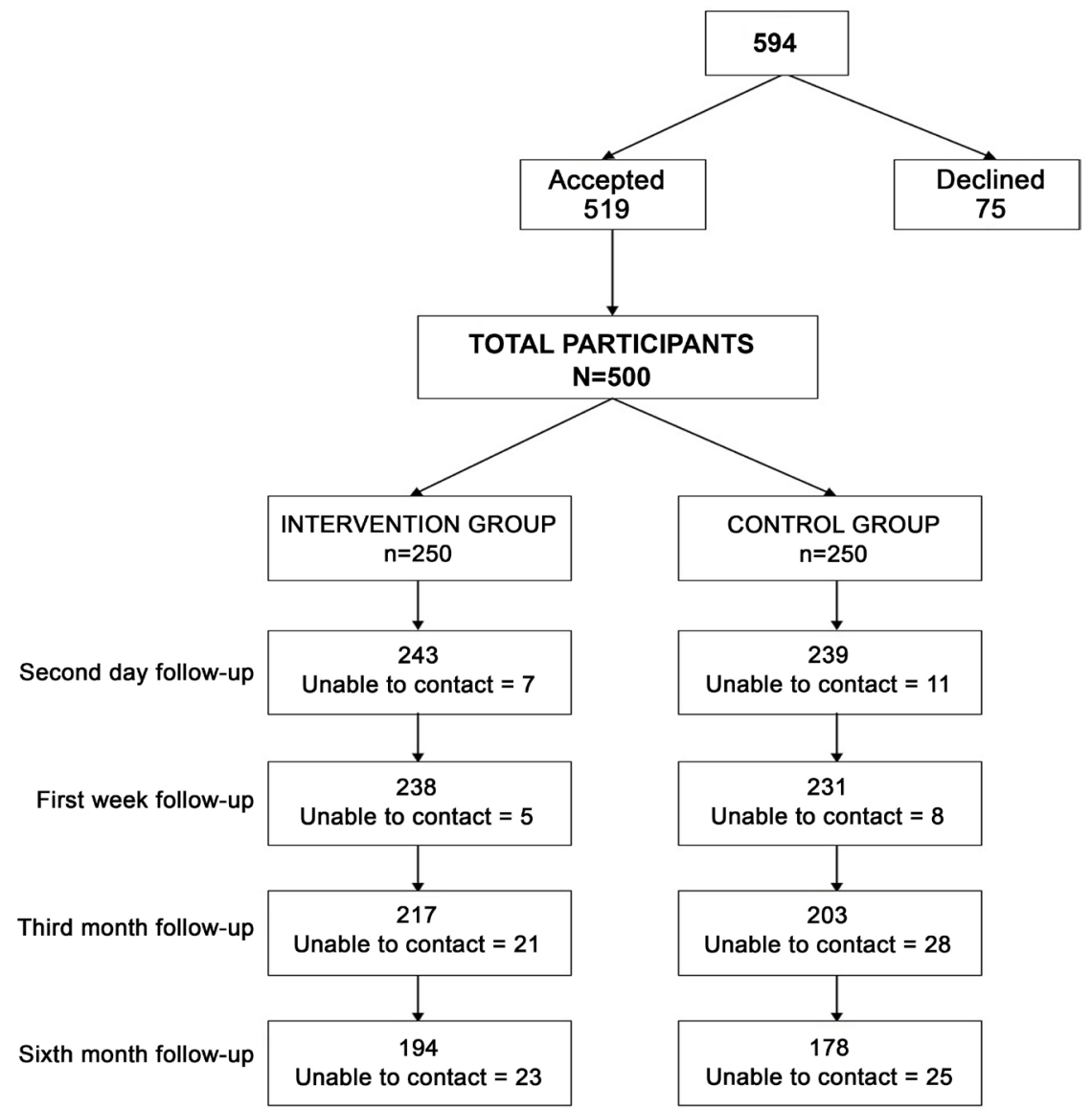

Figure 1. Flow of participating women during the study. 


\subsection{Statistical Analysis}

The data were entered and analyzed using SPSS software (Statistical Package for Social Sciences) version 21. The Kolmogorov-Smimov test was used for the study of variables. Thus, the Gaussian-distributed quantitative variables were expressed on the basis of the mean and standard deviations, while the non-Gaussian-distributed variables were expressed in median and quartiles. The qualitative variables were compared using Pearson chi-squared test or the Least Significant Difference test (LSD). We also used the Mann Whitney test to compare non-Gaussian-distributed variables. A value of $\mathrm{p}<0.05$ was considered significant for all statistical analyses.

\subsection{Ethical Considerations}

The study has received the approval of the administration of the Souissi Maternity Hospital in Rabat, as well as the approval of the ethics committee for biomedical research at the Faculty of Medicine and Pharmacy in Rabat, registered with the Office for Human Research Protection of the US Health and Human Services Department (Registration Number: IORG0006594). Medical secrecy and anonymity of the participants were rigorously respected. Besides, the process and purpose of the work were explained to all the mothers before filling the forms and informed consent was obtained. Every mother was free to leave the study any time she wished.

\section{Results}

\subsection{Population General Parameters}

The overall analysis of the 500 mothers surveyed (Table 1 ) revealed that the average age was 27 [23 - 31] with the extremes of 15 and 44 years. More than half of the participants live in urban areas (67.4\%) and most were housewives (90.4\%) with a level of education (primary, 33.2\%) (secondary, 44.8\%). As far as obstetrical history is concerned, the majority was primiparous (44.6\%) and followed up (97.4\%). In addition, $60.4 \%$ benefited from more than 5 pre-natal visits. Compared to neonatal data, the Apgar score was normal for almost all infants, and these had a birth weight ranging from $2500 \mathrm{~g}$ to $3500 \mathrm{~g}$. The analysis of the socio-demographic, prenatal and natal parameters of mothers and newborns in the intervention group and control group (Table 1) did not reveal any statistically significant differences in terms of age, living area, education level, mother's profession, number of children, medical follow-up, number of prenatal visits, Apgar score and birth weight. However, the distribution of the two groups in terms of the place of follow-up and delivery method was significantly unsimilar.

\subsection{Mothers' Knowledge and Practices in Terms of Breastfeeding}

The analysis of Table 2 shows that of the 500 women surveyed, only 81 (16.6\%) had received counselling on breastfeeding during the prenatal period, of whom 
Table 1. Sociodemographic, prenatal and natal parameters of mothers and newborns in the overall population and in the control and intervention groups.

\begin{tabular}{|c|c|c|c|c|}
\hline \multirow[b]{2}{*}{ Characteristics } & \multirow{2}{*}{$\begin{array}{l}\text { Global analysis } \\
\quad \mathrm{N}=500\end{array}$} & \multicolumn{2}{|c|}{ Bivariate analysis } & \multirow[b]{2}{*}{$p$} \\
\hline & & $\begin{array}{l}\text { Control group } \\
\mathrm{N}=250\end{array}$ & $\begin{array}{l}\text { Intervention group } \\
\qquad \mathrm{N}=250\end{array}$ & \\
\hline \multicolumn{5}{|l|}{ Characteristics of mothers } \\
\hline Age & $27[23-31]$ & $27[23-32]$ & $26\left[\begin{array}{ll}2 & 3-31]\end{array}\right.$ & 0.847 \\
\hline Place of residence & & & & 0.465 \\
\hline Urban & $337(67.4)$ & $172(68.8)$ & $165(66.0)$ & \\
\hline Suburban & $85(17.0)$ & $44(17.6)$ & $41(16.4)$ & \\
\hline Rural & $78(15.6)$ & $34(13.6)$ & $44(17.6)$ & \\
\hline Educational levels & & & & 0.180 \\
\hline Illiterate & $61(12.2)$ & $34(13.6)$ & $27(10.8)$ & \\
\hline Literacy courses & $16(3.2)$ & $8(3.2)$ & $8(3.2)$ & \\
\hline Primary & $166(33.2)$ & $93(37.2)$ & $73(29.2)$ & \\
\hline Secondary & $224(44.8)$ & $99(39.6)$ & $125(50.0)$ & \\
\hline University & $33(6.6)$ & $16(16.4)$ & $17(6.8)$ & \\
\hline Mother's profession & & & & 0.433 \\
\hline Housewife & $452(90.4)$ & $229(91.6)$ & $223(89.2)$ & \\
\hline Employee & $41(8.2)$ & $19(7.6)$ & $22(8.8)$ & \\
\hline Other & $7(1.4)$ & $2(0.8)$ & $5(2)$. & \\
\hline Number of children & & & & 0.384 \\
\hline 1 & $223(44.6)$ & $106(42.4)$ & $117(46.8)$ & \\
\hline 2 & $146(29.2)$ & $72(28.8)$ & $74(29.6)$ & \\
\hline 3 & $89(17.8)$ & $53(21.2)$ & $36(14.4)$ & \\
\hline 4 & $27(5.4)$ & $13(5.2)$ & $14(5.6)$ & \\
\hline 5 & $1(2.8)$ & $6(2.4)$ & $8(3.2)$ & \\
\hline$\geq 6$ & $1(0.2)$ & $0(0.0)$ & $1(0.4)$ & \\
\hline Pregnancy follow-up & & & & 0.399 \\
\hline No & $13(2.6)$ & $5(2.0)$ & $8(3.2)$ & \\
\hline Yes & $487(97.4)$ & $245(98.0)$ & $242(96.8)$ & \\
\hline Number of prenatal visits & & & & 0.123 \\
\hline 1 & $8(1.6)$ & $3(1.2)$ & $5(2.1)$ & \\
\hline 2 & $24(4.9)$ & $7(2.9)$ & $17(7.0)$ & \\
\hline 3 & $62(12.7)$ & $32(13.1)$ & $30(12.4)$ & \\
\hline 4 & $91(18.7)$ & $53(21.6)$ & $38(15.7)$ & \\
\hline$\geq 5$ & $302(60.4)$ & $150(61.2)$ & $152(62.8)$ & \\
\hline Place of follow-up & & & & 0.011 \\
\hline Public sector & $215(44.1)$ & $107(43.7)$ & $108(44.6)$ & \\
\hline
\end{tabular}




\section{Continued}

\begin{tabular}{ccccc}
\hline Private sector & $199(40.9)$ & $90(36.7)$ & $109(45.0)$ & \\
Both & $73(15.0)$ & $48(19.6)$ & $25(10.3)$ & \\
Mode of delivery & & & & 0.002 \\
Vaginal delivery without episiotomy & $168(33.6)$ & $68(27.2)$ & $100(40.0)$ & \\
Vaginal delivery with episiotomy & $332(66.4)$ & $182(72.8)$ & $150(60.0)$ & \\
Delivery by: & & & & 0.705 \\
Midwife & $332(66.4)$ & $168(67.2)$ & $164(65.6)$ & \\
Gynaecologist & $168(33.6)$ & $82(32.8)$ & $86(34.4)$ & \\
Characteristics of newborns & & & & \\
APGAR & & & & \\
$10 / 10 / 10$ & $492(98.4)$ & $245(98.0)$ & $247(98.8)$ & \\
$08 / 10 / 10$ & $4(0.8)$ & $2(0.8)$ & $2(0.8)$ & \\
$07 / 08 / 10$ & $2(0.4)$ & $1(0.4)$ & $1(0.4)$ & \\
$06 / 10 / 10$ & $2(0.4)$ & $2(0.8)$ & $0(0.0)$ & \\
Birth weight & & & & \\
2500 g - 3500 g & $363(72.6)$ & $179(71.6)$ & $184(73.6)$ & \\
$>3500 \mathrm{~g}$ & $137(27.4)$ & $71(28.4)$ & $66(26.4)$ & \\
\hline
\end{tabular}

Values are expressed as median and quartile or in count and percentage. A $p<0.05$ value is considered significant.

69.1\% had been sensitized about the benefits of breastfeeding. The majority of mothers $(88.6 \%)$ did not breastfeed in the delivery room, and among the 57 mothers who breastfed their infants, 26 (that is, $45.6 \%$ ) received practical help from a health professional to breastfeed their babies in the delivery room. It should be noted that the average time spent in the delivery room was 3 hours $[2$ - 4.22]. As far as knowledge about breastfeeding is concerned (Table 2), the analysis of our results shows that $96.4 \%$ know they should not wait for the production of milk, and more than $2 / 3$ of our participants know it is necessary to breastfeed in the delivery room. However, only 144 (that is, 28.8\%) know they should breastfeed the baby within 30 minutes of delivery. For 466 mothers (93.2\%), the time of the first breastfeeding was over 60 minutes. In $96 \%$ of cases, women gave nothing to their babies before the first breastfeeding and herbal tea was administered to $85 \%$ of the 20 infants who received a liquid before the first breastfeeding. We sought the difficulties in breastfeeding among our participants, and the analysis of our results revealed that 107 (27.4\%) had issues breastfeeding their babies, the difficulties occurred just after birth for almost all those women, mostly because of breast rejection ( $40.2 \%$ of mothers) or nipple condition, which was flat or retracted in $17.8 \%$ of mothers.

As far as good breastfeeding practices are concerned, we found that $99 \%$ of mothers breastfed their babies correctly. In the same vein, breast-taking was done correctly and sucking effectively by almost all infants. Regarding the continuation 
Table 2. Parameters related to mothers' breastfeeding knowledge and practices in the overall population and in control and intervention groups.

\begin{tabular}{|c|c|c|c|c|}
\hline \multirow[b]{2}{*}{ Characteristics } & \multirow{2}{*}{$\begin{array}{l}\text { Global } \\
\text { analysis } \\
\mathrm{n}=500\end{array}$} & \multicolumn{2}{|c|}{ Bivariate analysis } & \multirow[b]{2}{*}{$\mathbf{P}$} \\
\hline & & $\begin{array}{l}\text { Control } \\
\text { group } \\
n=250\end{array}$ & $\begin{array}{c}\text { Intervention } \\
\text { group } \\
\mathbf{n}=250\end{array}$ & \\
\hline \multicolumn{5}{|l|}{$\underline{\text { Knowledge }}$} \\
\hline Advice received during the prenatal visits & & & & 0.201 \\
\hline No & $406(83.4)$ & $199(81.2)$ & $207(85.5)$ & \\
\hline Yes & $81(16.6)$ & $46(18.8)$ & $35(14.5)$ & \\
\hline Type of advice & & & & 0.641 \\
\hline Latching on & $3(3.7)$ & $2(4.3)$ & $1(2.9)$ & \\
\hline Advantage of breast milk & $56(69.1)$ & $34(73.9)$ & $22(62.9)$ & \\
\hline Other & $2(2.5)$ & $1(2.2)$ & $1(2.9)$ & \\
\hline Two or more & $20(24.7)$ & $9(19.6)$ & $11(31.4)$ & \\
\hline Waiting for milky climb & & & & 0.001 \\
\hline Not obligatory & $482(96.4)$ & $233(9.2)$ & $249(99.6)$ & \\
\hline Obligatory & $15(3.0)$ & $14(5.6)$ & $1(0.4)$ & \\
\hline No answer & $3(0.6)$ & $3(0.6)$ & $0(0.0)$ & \\
\hline Put to the breast in delivery room & & & & 0.033 \\
\hline Not important & $97(19.4)$ & $51(20.4)$ & $46(18.4)$ & \\
\hline Important & $397(79.4)$ & $193(77.2)$ & $204(81.6)$ & \\
\hline No answer & $6(1.2)$ & $6(2.4)$ & $0(0.0)$ & \\
\hline Delay for breastfeeding after delivery & & & & 0.001 \\
\hline$<1 / 2$ hour & $144(28.8)$ & $89(35.6)$ & $55(22.0)$ & \\
\hline$<1$ hour & $194(38.8)$ & $87(34.8)$ & $107(42.8)$ & \\
\hline$<2$ hours & $96(19.2)$ & $48(19.2)$ & $48(19.2)$ & \\
\hline$<4$ hours & $50(10.0)$ & $14(5.6)$ & $36(14.4)$ & \\
\hline$<6$ hours & $4(0.8)$ & $1(0.4)$ & $3(1.2)$ & \\
\hline$>6$ hours & $2(0.4)$ & $1(0.4)$ & $1(0.4)$ & \\
\hline No answer & $10(2.0)$ & $10(4)$ & $0(0.0)$ & \\
\hline Envisaged duration of breastfeeding & & & & 0.432 \\
\hline$<6$ months & $3(0.6)$ & $2(0.8)$ & $1(0.4)$ & \\
\hline 6 à 12 months & $52(10.4)$ & $30(12)$ & $22(8.8)$ & \\
\hline$>12$ months & $445(89.0)$ & $218(87.2)$ & $227(90.8)$ & \\
\hline Reasons for the continuation of breastfeeding & & & & 0.001 \\
\hline Health and protection of the child & $175(35)$ & $74(29.6)$ & $101(40.4)$ & \\
\hline Health and protection of the mother & $1(0.2)$ & $0(0.0)$ & $1(0.4)$ & \\
\hline Health and protection of the child and the mother & $132(26.4)$ & $57(22.8)$ & $75(30.0)$ & \\
\hline
\end{tabular}




\section{Continued}

\begin{tabular}{|c|c|c|c|c|}
\hline Importance of breast milk & $126(25.2)$ & $96(38.4)$ & $30(12)$ & \\
\hline Nutrition of the child & $3(0.6)$ & $1(0.4)$ & $2(0.8)$ & \\
\hline No answer & $63(12.6)$ & $22(8.8)$ & $41(16.4)$ & \\
\hline \multicolumn{5}{|l|}{ Practices } \\
\hline Time spent in the delivery room & $3[2-4.22]$ & $\begin{array}{c}3[2.25- \\
4.04]\end{array}$ & $3[2-4.33]$ & 0.784 \\
\hline \multicolumn{5}{|l|}{ (in hour) } \\
\hline Breastfeeding in the delivery room & & & & 0.888 \\
\hline No & $443(88.6)$ & $222(88.8)$ & $221(88.4)$ & \\
\hline Yes & $57(11.4)$ & $28(11.2)$ & $29(11.6)$ & \\
\hline Help to breastfeed in the delivery room & & & & 0.045 \\
\hline Health professional & $26(45.6)$ & $9(32.1)$ & $17(58.6)$ & \\
\hline No one & $31(54.4)$ & $19(67.9)$ & $12(41.4)$ & \\
\hline Time of the first breastfeed & & & & 0.528 \\
\hline$<30 \mathrm{~min}$ & $2(0.4)$ & $1(0.4)$ & $0(0)$ & \\
\hline De 30 à $60 \mathrm{~min}$ & $32(6.4)$ & $18(7.2)$ & $14(5.6)$ & \\
\hline$>60 \mathrm{~min}$ & $466(93.2)$ & $231(92.4)$ & $236(94.4)$ & \\
\hline Liquid received before the first breastfeed & & & & 0.648 \\
\hline No & $480(96.0)$ & $241(96.4)$ & $239(95.6)$ & \\
\hline Yes & $20(4.0)$ & $9(3.6)$ & $11(0.4)$ & \\
\hline Type of liquid & & & & 0.711 \\
\hline water & $1(5)$ & $1(11.1)$ & $0(0.0)$ & \\
\hline Tisane & $17(85)$ & $7(77.8)$ & $10(90.9)$ & \\
\hline Artificial milk & $2(10)$ & $1(11.1)$ & $1(12.5)$ & \\
\hline Reasons for liquid administration & & & & 0.251 \\
\hline Waiting for the milky climb & $1(5)$ & $1(11.1)$ & $0(0.0)$ & \\
\hline Facilitate the elimination of meconium & $1(5)$ & $0(0.0)$ & $1(9.1)$ & \\
\hline Calming the baby's colic & $1(5)$ & $1(11.1)$ & $0(0.0)$ & \\
\hline Calming the baby's crying & $8(40)$ & $2(22.2)$ & $6(54.5)$ & \\
\hline Other & $9(45)$ & $5(55.6)$ & $4(36.4)$ & \\
\hline Means of administration & & & & 0.770 \\
\hline Baby bottle & $4(20)$ & $2(22.2)$ & $2(18.2)$ & \\
\hline Spoon & $15(75)$ & $6(66.7)$ & $9(81.8)$ & \\
\hline Glass & $0(0.0)$ & $0(0.0)$ & $0(0.0)$ & \\
\hline Other & $1(5)$ & $1(11.1)$ & $0(0.0)$ & \\
\hline Problems with breastfeeding & & & & 0.275 \\
\hline No & $393(78.6)$ & $202(80.8)$ & $191(76.4)$ & \\
\hline Yes & $107(21.4)$ & $48(19.2)$ & $59(23.6)$ & \\
\hline
\end{tabular}




\section{Continued}

\begin{tabular}{|c|c|c|c|c|}
\hline Timing of problems & & & & 0.199 \\
\hline Just after birth & $105(98.1)$ & $46(95.8)$ & $59(100.0)$ & \\
\hline Other & $2(1.9)$ & $2(4.2)$ & $0(0.0)$ & \\
\hline Type of problems & & & & 0.220 \\
\hline Refusal of breast & $43(40.2)$ & $19(39.6)$ & $24(40.7)$ & \\
\hline Insufficient milk & $11(10.3)$ & $2(4.2)$ & $9(15.3)$ & \\
\hline Flat or umbilical nipples & $19(17.8)$ & $7(14.6)$ & $12(20.3)$ & \\
\hline Painful nipples & $2(1.9)$ & $2(4.2)$ & $0(0.0)$ & \\
\hline Cracked nipples & $4(3.7)$ & $3(6.2)$ & $1(1.7)$ & \\
\hline Pain related to episiotomy & $0(0.0)$ & $0(0.0)$ & $0(0.0)$ & \\
\hline Other & $15(14.0)$ & $8(16.7)$ & $7(11.9)$ & \\
\hline Two or more problems & $13(12.1)$ & $7(14.6)$ & $6(10.2)$ & \\
\hline Nipple & & & & 0.009 \\
\hline Normal & $414(82.8)$ & $218(87.2)$ & $196(78.4)$ & \\
\hline Flat or retracted & $86(17.2)$ & $32(12.8)$ & $54(21.6)$ & \\
\hline Assessment of lactogenesis & & & & 1.000 \\
\hline No changes & $224(44.8)$ & $112(44.8)$ & $112(44.8)$ & \\
\hline Slight increase & $271(54.2)$ & $135(54.0)$ & $136(54.4)$ & \\
\hline Significant increase & $5(1.0)$ & $3(1.2)$ & $2(0.8)$ & \\
\hline Discomfort / Severe pain/ Fever & $0(0.0)$ & $0(0.0)$ & $0(0.0)$ & \\
\hline Correct position of the newborn & & & & 0.061 \\
\hline No & $5(1.0)$ & $5(2.0)$ & $0(0.0)$ & \\
\hline Yes & $495(99.0)$ & $245(98.0)$ & $250(100.0)$ & \\
\hline Correct breast taking & & & & 0.371 \\
\hline No & $50(10.0)$ & $22(8.8)$ & $28(11.2)$ & \\
\hline Yes & $450(90.0)$ & $228(91.2)$ & $222(88.8)$ & \\
\hline Effective sucking & & & & 0.271 \\
\hline No & $60(12.0)$ & $26(10.4)$ & $34(13.6)$ & \\
\hline Yes & $440(88.0)$ & $224(89.6)$ & $216(86.4)$ & \\
\hline
\end{tabular}

Values are expressed as median and quartile or in count and percentage. A p $<0.05$ value is considered significant.

of breastfeeding, we noticed that 445 mothers (89\%) intended to breastfeed their babies for more than 12 months. On the other hand, Table 2 summarizes the distribution of parameters in relation to mothers' breastfeeding knowledge and practices in the control group and intervention group. The analysis of the results obtained allowed to highlight a statistically significant difference between the two populations concerning only the expectation of milk production $(\mathrm{p}<0.000)$, breastfeeding in the delivery room $(\mathrm{p}=0.033)$, and the time within which the baby should 
be breastfed after delivery $(\mathrm{p}<0.001)$.

\subsection{Analysis of Follow-Up Data of Breastfeeding Mothers in Terms of EB}

Overall, 372 (178 from the control group, and 194 from the intervention group) of the 500 women surveyed could be followed and answered all of our telephone calls during the second stage of our survey (Table 3); that is, a participation rate of $74.4 \%$ in the overall population and a rate of $71.2 \%$ and $77 \%$ in the control group and intervention group, respectively, and the rest of women were lost sight of. The analysis of Table 3, representing the distribution of breastfeeding women followed according to the practice of EB over time in the two groups, showed that the continuation of EB until the age of 6 months was significantly high among mothers in the intervention group compared to the control group (55.2\% against $38.8 \%, \mathrm{p}=0.002$ ). Table 3 also summarizes the alternative feeding modalities of infants as well as the reason for ceasing EB. It became clear that pharmacy milk was the most common nutrition method, and that milk insufficiency or the difficulty to breastfeed are the main causes of the discontinuation of EB in both the control group and the intervention group.

\section{Discussion}

The present study shows that the education offered on the first day after delivery, based on a pedagogical program dealing with breastfeeding through the distribution of educational booklets (subject of the study) and associated with a short support session and oral education, has proven effective in promoting exclusive breastfeeding for the first six months of a baby's life. On the $2^{\text {nd }}$ day, in 1 week and 3 months following delivery, the percentage of mothers who exclusively breastfed their infants is almost similar between the two groups (respectively, 178/194 (91.8\%) against 164/178 (92.1\%) “p = 0.892"; 173/194 (89.2\%) against 155/178 (87.1\%) "p = 0.532”; 148/194 (76.3\%) against 126/178 (70.8\%) “p = 0.229”). However, a higher percentage of mothers in the intervention group exclusively breastfed their babies until the age of 6 months, compared to the control group, that is, $107 / 194(55.2 \%)$ against $69 / 178(38.8 \%)$ with a statistically very significant difference of $\mathrm{p}=0.002$, which proved that the educational booklet has a positive impact on the duration of EB. The parameters of previous studies in this context vary and lack comparability. For instance, the study of Mattar et al. revealed a marginal increase in $\mathrm{EB}$ at six months after delivery among the group which received a prenatal educational intervention highlighting the benefits as well as the management of breastfeeding issues as the main content of the educational material (booklet), video, coaching session and counselling, compared to the group receiving only the booklet and the video, and the one recipient of only routine prenatal care, concluding that that educational material alone in the prenatal period is not enough and that specific prenatal education that addresses breastfeeding following a single meeting through counselling can significantly improve 
Table 3. Distribution of followed breastfeeding women according to exclusive breastfeeding practice over time in the control and intervention groups.

\begin{tabular}{|c|c|c|c|}
\hline \multirow[b]{2}{*}{ Variables } & \multicolumn{2}{|c|}{ Population N = 372} & \multirow[b]{2}{*}{$\mathrm{p}$} \\
\hline & $\begin{array}{l}\text { Control group } \\
n=178\end{array}$ & $\begin{array}{l}\text { Intervention group } \\
\qquad \mathrm{n}=194\end{array}$ & \\
\hline \multicolumn{4}{|l|}{ Duration of EB } \\
\hline EB at 2 days & & & 0.892 \\
\hline No & $14(7.9)$ & $16(8.2)$ & \\
\hline Yes & $164(92.1)$ & $178(91.8)$ & \\
\hline EB at 1 week & & & 0.532 \\
\hline No & $23(12.9)$ & $21(10.8)$ & \\
\hline Yes & $155(87.1)$ & $173(89.2)$ & \\
\hline EB at 3 months & & & 0.229 \\
\hline No & $52(29.2)$ & $46(23.7)$ & \\
\hline Yes & $126(70.8)$ & $148(76.3)$ & \\
\hline EB at 6 months & & & 0.002 \\
\hline No & $109(61.2)$ & $87(44.8)$ & \\
\hline Yes & $69(38.8)$ & $107(55.2)$ & \\
\hline Nutrition mode after stopping EB & & & 0.107 \\
\hline Breast and PM & $63(57.8)$ & $56(64.4)$ & \\
\hline Breast and $\mathrm{CM}$ & $2(1.8)$ & $3(3.4)$ & \\
\hline Breast and CF & $36(33)$ & $17(19.5)$ & \\
\hline FM alone & $7(6.4)$ & $11(12.6)$ & \\
\hline Breast and $\mathrm{PM}$ and $\mathrm{CM}$ & $1(0.9)$ & $0(0)$ & \\
\hline Reasons for discontinuing EB & & & 0.124 \\
\hline Child's disease & $5(4.6)$ & $2(2.3)$ & \\
\hline Return to work & $8(7.3)$ & $9(10.3)$ & \\
\hline Insufficient milk & $45(41.3)$ & $32(36.8)$ & \\
\hline Mother's disease & $0(0)$ & $3(3.4)$ & \\
\hline Occurrence of new pregnancy & $0(0)$ & $3(3.4)$ & \\
\hline Difficulty in sucking & $41(37.6)$ & $34(39.1)$ & \\
\hline Other & $10(9.2)$ & $4(4.6)$ & \\
\hline
\end{tabular}

Values are expressed as median and quartile or in count and percentage. EB: exclusive breastfeeding; PM: pharmacy milk; CM: cow milk; CF: complementary food. A p $<0.05$ value is considered significant.

breastfeeding practice [19]. Besides, the results of Gijsbers et al. showed that the educational program based on written advice in booklets as well as data delivered orally about all the aspects of breastfeeding and milk storage and expression proved effective in improving EB rates up to 6 months for pregnant women of a child with an asthma predisposition, visited twice before the birth of their babies and 
once afterwards [20]. Another study had been conducted by Yvonne et al. to assess the impact of the distribution of educational booklets during the postnatal period, but this time over the duration of complete breastfeeding, and the result was an insignificant difference noted for the duration of breastfeeding between the study group and the control group [21].

Our results support current evidence for educational intervention since mothers with more information about $\mathrm{EB}$, and therefore more knowledge, are more likely to practice it than their counterparts who lack enough information. This proves, once again, that the level of knowledge is a factor strongly linked to the practice of EB. These results are supported by the study conducted by Sriram et al. and that of Mogre et al. revealing the relation between high prevalence of EB and better maternal knowledge in the field [22] [23]. Other studies concluded that the majority of mothers who do not exclusively breastfeed their babies have a lower level of knowledge [10] [24].

Resort to more than one method of education and support in the present study (booklets + oral counselling) has proved more effective than choosing one (oral counselling) to improve mothers' knowledge, and consequently, continue to exclusively breastfeed until the age of 6 months. It has been reported in systematic reviews that educational interventions based on different methods have proved more effective than those focused solely on a simple method [25], the same conclusion discussed by Tahir et al. urging them to think about establishing different support methods according to mothers' needs during the postpartum period [26].

The strategy adopted during our intervention is based on face-to-face support. First, through short oral training, and then through the distribution of educational materials in the form of booklets encouraging women to read and follow the instructions enshrined therein as they would guide them throughout the postnatal period. The strategy has been successful in extending the duration of EB, a result supported by a systematic review which has shown that non face-to-face support strategies are ineffective in promoting breastfeeding [27].

Our intervention was conducted shortly after delivery, so we focused mainly on the postnatal period, which yielded good results showing an improvement of EB practice. It had been stated in a study that the advice given during the postnatal visit on infant nutrition is positively related to the duration of $\mathrm{EB}$, thus reducing the risk of discontinuation [28]. A systematic review supports these results, indicating that the postnatal phase is probably the key period and the most adequate time to promote $\mathrm{EB}$ since the vast majority of successful interventions began in this period [29].

In this study, the main reasons for stopping EB in the course of the first six months, according to mothers in both groups, were milk insufficiency and breastfeeding difficulties. A study found four main reasons for the cessation of breastfeeding among which are: the perception of inadequate milk supply and chest discomfort, including nipple pain, which reflects breastfeeding difficulty [30]. Brown 
et al. reported that mothers' concerns about milk supply were often identified as an important reason for their decision to stop breastfeeding during the first six months [31]. Such finding was also evoked by Gatti, indicating that the perception of inadequate milk supply is put forth by mothers as the main reason for breastfeeding discontinuation during the first four weeks after delivery and also the most common reason for early cessation [32] and total cessation of breastfeeding [33]. As far as sucking difficulty is concerned, it has been reported that cracked nipples are one of the four variables assessed and associated with an early discontinuation of EB [34].

According to our results, the alternative nutritional method in case of discontinuation of EB is primarily breast with pharmacy milk, and according to the literature and this study, the concern about milk insufficiency and breastfeeding difficulties present common reasons for the introduction of the infant formula [10] [24]. The second method chosen by the mothers followed in our study is the breast with complementary foods.

The most important thing in this work is that our intervention based on educational materials has been successful, reaching $55.2 \%$ of babies' breastfed exclusively until the age of six months. This percentage is higher compared to the one reflecting the situation in Morocco in 2011, which was 27.8\%, and slightly lower than the target set by the National Nutrition Strategy for 2019, which is $60 \%$ [13] [14]. Therefore, the adoption of this educational intervention by health professionals and relevant institutions could significantly improve EB rates in the coming years in order to achieve the objectives of the action plan of the Health Ministry and, evidently, of WHO.

In our work, we found that the majority of women surveyed in this study did not receive breastfeeding counselling during the prenatal visit (83.4\%), and that most of them were unable to breastfeed in the delivery room (88.6\%), which supports the results that $93.2 \%$ of women were not able to breastfeed their babies until after the first hour after delivery despite the nutritional importance of colostrum. As a result, the level of knowledge, and consequently the practice, of mothers is not encouraging in the promotion of $\mathrm{EB}$, which explains the decline in rates over the years. Hence the need to strengthen the skills of health professionals in terms of infant nutrition [14], notably in breastfeeding.

\section{Limitation of the Study}

The difficulty of following the 500 women recruited given the number of lost to follow-up (unable to reach them by telephone).

\section{Conclusion}

The educational intervention assessing the efficiency of booklets during the postpartum period with regard to the practice of EB has achieved a significant percentage of exclusively breastfed babies until the age of six months. Such a result will encourage the adoption of these forms of support and finding more effective meas- 
ures to improve EB rates in Morocco. Therefore, a next step will be to make this program available to health professionals in order to support pregnant women first through prenatal education, and then women who have just delivered through postnatal education.

\section{Acknowledgements}

We extend our thanks to all participants for their contribution.

\section{Conflict of Interests}

The authors declare that they have no conflict of interest in relation to this article.

\section{Authors' Contributions}

Amina Barkat and Amina Bennis conceived and designed the study; Amina Bennis recruited and conducted the onsite survey of mothers; Amina Bennis and Fatima Zahra Laamiri analyzed, verified and interpreted the data; Aicha Kharbach, Hassan Aguenaou, Anas Ansari Chebguiti, and Mustapha Mrabet helped to design the study and critically revised the manuscript. Amina Bennis wrote the paper. All the authors read and approved the final manuscript.

\section{References}

[1] Rollins, N.C., Bhandari, N., Hajeebhoy, N., Horton, S., Lutter, C.K., Martines, J.C. and Victora, C.G. (2016) Why Invest, and What It Will Take to Improve Breastfeeding Practices? The Lancet, 387, 491-504. https://doi.org/10.1016/S0140-6736(15)01044-2

[2] Kellams, A.L., Gurka, K.K., Hornsby, P.P., Drake, E., Riffon, M., Gellerson, D., Gulati, G. and Coleman, V. (2016) The Impact of a Prenatal Education Video on Rates of Breastfeeding Initiation and Exclusivity during the Newborn Hospital Stay in a Low-Income Population. Journal of Human Lactation, 32, 152-159. https://doi.org/10.1177/0890334415599402

[3] Sankar, M.J., Sinha, B., Chowdhury, R., Bhandari, N., Taneja, S., Martines, J. and Bahl, R. (2015) Optimal Breastfeeding Practices and Infant and Child Mortality: A Systematic Review and Meta-Analysis. Acta Pædiatrica, 104, 3-13. https://doi.org/10.1111/apa.13147

[4] Lenja, A., Demissie, T., Yohannes, B. and Yohannis, M. (2016) Determinants of Exclusive Breastfeeding Practice to Infants Aged Less than Six Months in Offa District, Southern Ethiopia: A Cross-Sectional Study. International Breastfeeding Journal, 11, 1-7.

[5] Victora, C.G., Bahl, R., Barros, A.J., França, G.V, Horton, S., Krasevec, J., Murch, S., Sankar, M.J., Walker, N. and Rollins, N.C. (2016) Breastfeeding in the 21st Century: Epidemiology, Mechanisms, and Lifelong Effect. The Lancet, 387, 475-490. https://doi.org/10.1016/S0140-6736(15)01024-7

[6] American Academy of Pediatrics (2012) Breastfeeding and the Use of Human Milk. Pediatrics, 129, e827-e841. https://doi.org/10.1542/peds.2011-3552

[7] Lumbiganon, P., Martis, R., Laopaiboon, M., Festin, M.R., Ho, J.J. and Hakimi, M. (2016) Antenatal Breastfeeding Education for Increasing Breastfeeding Duration 
(Review). Cochrane Database of Systematic Reviews, 2016, CD006425. https://doi.org/10.1002/14651858.CD006425.pub4

[8] Grace, T., Oddy, W., Bulsara, M. and Hands, B. (2017) Breastfeeding and Motor Development: A Longitudinal Cohort Study. Human Movement Science, 51, 9-16. https://doi.org/10.1016/j.humov.2016.10.001

[9] Schreck, P.K., Solem, K., Wright, T., Schulte, C., Ronnisch, K.J. and Szpunar, S. (2017) Both Prenatal and Postnatal Interventions Are Needed to Improve Breastfeeding Outcomes in a Low-Income Population. Breastfeeding Medicine, 12, 142-148. https://doi.org/10.1089/bfm.2016.0131

[10] Zielińska, M.A., Sobczak, A. and Hamułka, J. (2017) Breastfeeding Knowledge and Exclusive Breastfeeding of Infants in First Six Months of Life. Roczniki Panstwowego Zakladu Higieny, 68, 51-59.

[11] World Health Organization (2008) Indicators for Assessing Infant and Young Child Feeding Practices. Part I: Definition. Geneva.

[12] McFadden, A., Gavine, A., Renfrew, M.J., Wade, A., Buchanan, P., Taylor, J.L., Veitch, E., Rennie, A.M., Crowther, S.A., Neiman, S. and MacGillivray, S. (2017) Support for Healthy Breastfeeding Mothers with Healthy Term Babies (Review). Cochrane Database of Systematic Reviews, 2, CD001141.

[13] International Baby Food Action Network “IBFAN" (2014) Report on the Situation of Infant and Young Child Feeding in Morocco. The Convention on the Rights of the Child, Session 67.

[14] Ministère de la santé-Royaume du Maroc. La Stratégie Nationale de la Nutrition 2011-2019. UNICEF. https://www.unicef.org/morocco/french/Strategie_Nationale_de_Nutrition_.pdf

[15] Meedya, S., Fahy, K. and Kable, A. (2010) Factors That Positively Influence Breastfeeding Duration to 6 Months: A Literature Review. Women Birth, 23, 135-145. https://doi.org/10.1016/j.wombi.2010.02.002

[16] Meedya, S., Fahy, K., Yoxall, J. and Parratt, J. (2014) Increasing Breastfeeding Rates to Six Months among Nulliparous Women: A Quasi-Experimental Study. Midwifery, 30, e137-e144. https://doi.org/10.1016/j.midw.2013.12.010

[17] Renfrew, M.J., McCormick, F.M., Wade, A., Quinn, B. and Dowswell, T. (2012) Support for Healthy Breastfeeding Mothers with Healthy Term Babies. Cochrane Database of Systematic Reviews, 2012, CD001141.

[18] Binns, C., Lee, M. and Low, W.Y. (2016) The Long-Term Public Health Benefits of Breastfeeding. Asia-Pacific Journal of Public Health, 28, 7-14. https://doi.org/10.1177/1010539515624964

[19] Mattar, C.N., Chong, Y.S., Chan, Y.S., Chew, A., Tan, P., Chan, Y.H. and Rauff, M.H. (2007) Simple Antenatal Preparation to Improve Breastfeeding Practice: A Randomized Controlled Trial. Obstetrics and Gynecology, 109, 73-80. https://doi.org/10.1097/01.AOG.0000249613.15466.26

[20] Gijsbers, B., Mesters, I., Knottnerus, J.A., Kester, A.D.M. and Van Schayck, C.P. (2006) The Success of an Educational Program to Promote Exclusive Breastfeeding for 6 Months in Families with a History of Asthma: A Randomized Controlled Trial. Pediatric Asthma Allergy and Immunology, 19, 214-222. https://doi.org/10.1089/pai.2006.19.214

[21] Hauck, Y.L. and Dimmock, J.E. (1994) Evaluation of an Information Booklet on Breastfeeding Duration: A Clinical Trial. Journal of Advanced Nursing, 20, 836-843. https://doi.org/10.1046/j.1365-2648.1994.20050836.x 
[22] Sriram, S., Soni, P., Thanvi, R., Prajapati, N. and Mehariya, K.M. (2013) Knowledge, Attitude and Practices of Mothers Regarding Infant Feeding Practices. National Journal of Medical Research, 3, 147-150.

[23] Mogre, V., Dery, M. and Gaa, P.K. (2016) Knowledge, Attitudes and Determinants of Exclusive Breastfeeding Practice among Ghanaian Rural Lactating Mothers. International Breastfeeding Journal, 11, 1-8.

[24] Majchrzak, M., Stawicka, K., Jenczura, A., Czajkowska, M., Pyrcek, A., Mann, A., Ociepa, K. and Płonka, J. (2014) Czynniki determinujące sposoby karmienia noworodków i małych dzieci. [Factors Determining Ways of Feeding Infants and Young Children.] Zdrowie i Dobrostan, 3, 79-87.

[25] Hannula, L., Kaunonen, M. and Tarkka, M.T. (2008) A Systematic Review of Professional Support Interventions for Breastfeeding. Journal of Clinical Nursing, 17, 1132-1143. https://doi.org/10.1111/j.1365-2702.2007.02239.x

[26] Tahir, N.M. and Al-Sadat, N. (2013) Does Telephone Lactation Counselling Improve Breastfeeding Practices? A Randomised Controlled Trial. International Journal of Nursing Studies, 50, 16-25. https://doi.org/10.1016/j.ijnurstu.2012.09.006

[27] Sikorski, J., Renfrew, M.J., Pindoria, S. and Wade, A. (2003) Support for Breastfeeding Mothers: A Systematic Review. Paediatric and Perinatal Epidemiology, 17, 407-417. https://doi.org/10.1046/j.1365-3016.2003.00512.x

[28] Kasahun, A.W., Wako, W.G., Gebere, M.W. and Neima, G.H. (2017) Predictors of Exclusive Breastfeeding Duration among 6-12 Month Aged Children in Gurage Zone, South Ethiopia: A Survival Analysis. International Breastfeeding Journal, 12, 1-9.

[29] Skouteris, H., Nagle, C., Fowler, M., Kent, B., Sahota, P. and Morris, H. (2014) Interventions Designed to Promote Exclusive Breastfeeding in High-Income Countries: A Systematic Review. Breastfeeding Medicine, 9, 113-127. https://doi.org/10.1089/bfm.2013.0081

[30] Kirkland, V.L. and Fein, S.B. (2003) Characterizing Reasons for Breastfeeding Cessation throughout the First Year Postpartum using the Construct of Thriving. Journal of Human Lactation, 19, 278-285. https://doi.org/10.1177/0890334403255229

[31] Brown, C.R., Dodds, L., Legge, A., Bryanton, J. and Semenic, S. (2014) Factors Influencing the Reasons Why Mothers Stop Breastfeeding. Canadian Journal of Public Health, 105, e179-e185. https://doi.org/10.17269/cjph.105.4244

[32] Gatti, L. (2008) Maternal Perceptions of Insufficient Milk Supply in Breastfeeding. Journal of Nursing Scholarship, 40, 355-363. https://doi.org/10.1111/j.1547-5069.2008.00234.x

[33] Olang, B., Heidarzadeh, A., Strandvik, B. and Yngve, A. (2012) Reasons Given by Mothers for Discontinuing Breastfeeding in Iran. International Breastfeeding Journal, 7, 1-7.

[34] Vieira, G.O., Martins, C.C., Vieira, T.O., Oliveira, N.F. and Silva, L.R. (2010) Factors Predicting Early Discontinuation of Exclusive Breastfeeding in the First Month of Life. Jornal de Pediatria, 86, 441-444. https://doi.org/10.1590/S0021-75572010000500015 